\title{
High prevalence of vitamin D deficiency in the sunny Eastern region of Saudi Arabia: a hospital-based study
}

\author{
M.Y. Elsammak, ${ }^{7}$ A.A. Al-Wossaibi, ${ }^{2}$ A. Al-Howeish ${ }^{3}$ and J. Alsaeed ${ }^{2}$
}

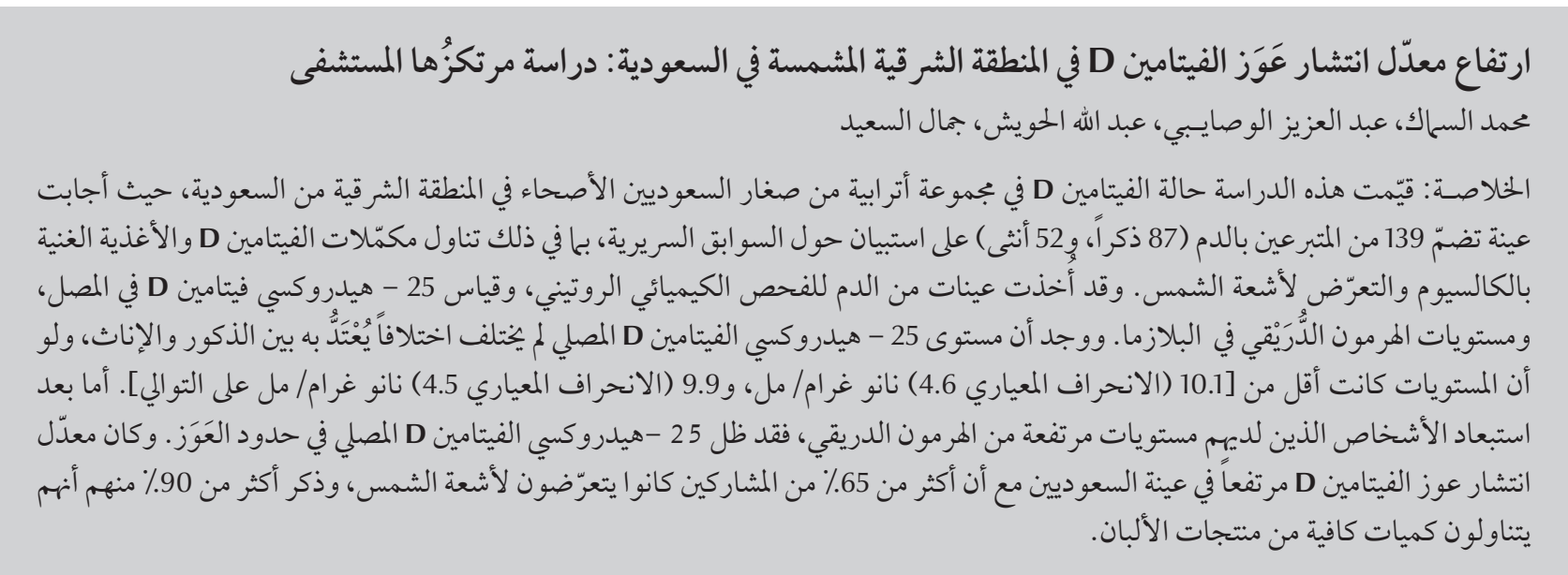

ABSTRACT This study evaluated the vitamin D status of a cohort of healthy young Saudi Arabians in the Eastern region of Saudi Arabia. A sample of 139 blood donors (87 males and 52 females) answered a questionnaire about their clinical history, including intake of vitamin D supplements and calcium-rich foods and exposure to sunshine. Blood samples were taken for routine biochemistry, serum 25-hydroxyvitamin D [25(OH)3] and plasma parathyroid hormone (PTH) levels. Serum 25(OH)D levels did not differ significantly between males and females, although the levels were low $[10.1$ (SD 4.6) ng/mL and 9.9 (SD 4.5) ng/mL respectively]. When subjects with elevated PTH levels were excluded, serum 25(OH)3 levels were still in the deficiency range. There was a high prevalence of a vitamin D deficiency in this sample of Saudi Arabians despite $>65 \%$ of participants having adequate exposure to sunlight and $>90 \%$ reporting adequate intake of dairy products.

Prévalence élevée de carence en vitamine D dans la région ensoleillée de l'est de l'Arabie saoudite : une étude en milieu hospitalier

RÉSUMÉ La présente étude a évalué le statut en vitamine D d'une cohorte de jeunes saoudiens en bonne santé résidant dans la région de l'est de l'Arabie saoudite. Les 139 donneurs de sang de l'échantillon (87 hommes et 52 femmes) ont rempli un questionnaire portant sur leurs antécédents médicaux. Les répondants devaient aussi préciser s'ils prenaient des compléments en vitamine D, quelle était leur consommation d'aliments riches en calcium et dans quelle mesure ils s'exposaient au soleil. Des échantillons sanguins ont été recueillis pour des analyses biochimiques classiques, à savoir le dosage sérique de la 25-Hydroxyvitamine D [25(OH)3] et les taux plasmatiques de l'hormone parathyroïde. Les valeurs sériques de la 25-Hydroxyvitamine D n'étaient pas significativement différentes entre les hommes et les femmes, même si ces valeurs étaient faibles $(10,1 \mathrm{ng} / \mathrm{ml}$ [E.T. 4,6] et 9,9 ng/ml [E.T. 4,5], respectivement). Lorsque les patients présentant des taux élevés d'hormone parathyroïde ont été exclus, les taux sériques de la 25-Hydroxyvitamine D se situaient toujours dans la plage correspondant à une carence. L'échantillon de Saoudiens étudié présentait une prévalence élevée de carence en vitamine $\mathrm{D}$ en dépit d'une exposition solaire adéquate pour plus de $65 \%$ des participants et d'une consommation appropriée de produits laitiers pour plus de 90 \% d'entre eux. 


\section{Introduction}

Vitamin D is an important nutrient for healthy bones and a deficiency of the vitamin may result in metabolic bone diseases leading to rickets in children or osteomalacia in adults $[1,2]$. The vitamin $\mathrm{D}$ level is regulated through the interaction of various factors, including intestinal absorption, renal function, serum calcium level and parathyroid hormone (PTH) [3]. The 2 main sources for vitamin $\mathrm{D}$ are dietary intake and synthesis in the skin on exposure to ultraviolet- $B$ (UVB) light from sunlight [4]. Skin pigmentation may play an important role in determining vitamin $\mathrm{D}$ levels as darker skin colour may limit the amount of UVB light that penetrates, thereby reducing the cutaneous synthesis of vitamin D [5].

Serum 25-hydroxyvitamin D $[25(\mathrm{OH}) \mathrm{D}]$ level is considered to be the best indicator of vitamin $\mathrm{D}$ status, with reference ranges from 15 or 16 $\mathrm{ng} / \mathrm{mL}$ to more than 40 or $48 \mathrm{ng} / \mathrm{mL}$ [6]. A 25(OH)D level below $8 \mathrm{ng} /$ $\mathrm{mL}$ (the threshold for development of rickets/osteomalacia) has usually been termed vitamin $\mathrm{D}$ insufficiency [7]. Another important measure is the serum PTH level which increases in response to insufficient calcium in order to stimulate bone resorption and increase the serum calcium necessary for the different biological processes in the body, e.g. muscle contraction and nerve conduction [8]. Many studies have reported an inverse association between serum PTH concentrations and serum 25( $\mathrm{OH}) \mathrm{D}$ concentrations [9-11].

In areas such as Saudi Arabia where there is plentiful sunlight and many food products are fortified with vitamin $\mathrm{D}$, it would be expected that the vitamin D level would be adequate in the majority of the population. Despite some cultural factors that may negatively affect serum vitamin $D$ levels of Saudi women (e.g. high gravidity and clothing that limits skin exposure to the sun), these factors do not apply to males and hence vitamin $\mathrm{D}$ ranges may be expected to be different between males and females. In our practice in the Eastern region of Saudi Arabia we noted that a substantial proportion of patients as well as healthy subjects coming for routine screening have subnormal levels of vitamin $\mathrm{D}$. The aim of this study was to measure the vitamin $\mathrm{D}$ level in a cohort of blood donors in order to evaluate the vitamin D status of healthy adult Saudi Arabians.

\section{Methods}

\section{Sample}

Subjects included in this study were coming for routine checkups before blood donation at King Fahd hospital, Dammam, Saudi Arabia. All of them were Saudi nationals living in the Eastern region of Saudi Arabia and were apparently healthy with no associated medical problems. The study was approved by King Fahd University hospital ethical committee. All subjects gave their consent to participate in the study.

The sample was 139 subjects ( 87 males and 52 females). A total of 176 subjects were initially included in the study, 139 met the inclusion criteria and 61 were excluded from the study due to various reasons ( 7 had recent viral infection, 15 were taking vitamin $D$ and calcium supplements, 10 had unexplained elevation of liver function, 3 had elevated serum creatinine and 2 were on lithium therapy). The study was carried out during winter between December 2008 and March 2009. Average winter temperatures in the Eastern region are $18-25^{\circ} \mathrm{C}$ during daytime.

A full clinical examination and clinical history were taken from all subjects participating in the study. Exclusion criteria included: any acute or chronic illness, liver or renal, endocrine or autoimmune disease, taking any regular medication which can affect vitamin D level (e.g. vitamin D or calcium supplementation, phenytoin), elevated PTH level or impaired renal function.

\section{Data collection}

In addition to the clinical examination, participants were given a questionnaire addressing their frequency of sun exposure, daily intake of dairy products, history of vitamin D or calcium supplementation, history of bone aches or pains and intake of any medications that could affect vitamin D metabolism. Adequate intake of dairy products was defined as $200 \mathrm{~mL}$ of fortified milk, $50 \mathrm{~g}$ of cheddar cheese and 1 pot of yoghurt. Adequate exposure to sunlight was defined as regular exposure at least twice a week between 09.00-12.00 hours for 40 minutes with at least forearms and legs exposed to directsunlight. Weight, height and blood pressure were recorded.

A $10 \mathrm{~mL}$ blood sample was taken from each participant. An aliquot of blood was taken on EDTA for haemoglobin measurement. Blood was centrifuged and serum was separated and analysed promptly. Laboratory studies included measurement of random glucose, urea, creatinine, uric acid, calcium, phosphorous, alkaline phosphatase, total protein and albumin and alanine transaminase (ALT). These parameters were measured using a clinical chemistry analyser (Dimension RxL, Siemens Diagnostics). Serum intact PTH level was measured using an immunoassay analyser (Architect 2000i, Abbott), while serum $25(\mathrm{OH}) \mathrm{D}$ was measured using a chemiluminescence immunoassay analyser (Liaison, Diasorin) The intra-assay coefficient of variation was $11.6 \%$. Both high and low quality control materials were included with each run and verified to be within the expected quality control ranges before accepting the results.

The reference ranges used in our laboratory for $25 \mathrm{OH}$ vitamin $\mathrm{D}$ were as follows: $0-5 \mathrm{ng} / \mathrm{mL}$ (deficiency), 5-39 $\mathrm{ng} / \mathrm{mL}$ (insufficiency) and $40-100$ $\mathrm{ng} / \mathrm{mL}$ (sufficiency). The reference range for other variables were: PTH 15-68.3 pg/mL, haemoglobin $12-17$ $\mathrm{g} / \mathrm{dL}$, urea $2.7-7.2 \mathrm{mmol} / \mathrm{L}$, creatinine 71-115 $\mu \mathrm{mol} / \mathrm{L}$, uric acid $155-357$ 
$\mu \mathrm{mol} / \mathrm{L}$, calcium $2.22-2.64 \mathrm{mmol} / \mathrm{L}$, phosphorous $0.7-1.5 \mathrm{mmol} / \mathrm{L}$, alkaline phosphatase 54-144 U/L, ALT 17-49 $\mathrm{U} / \mathrm{L}$, total protein $64-82 \mathrm{~g} / \mathrm{L}$ and albu$\min 34-50 \mathrm{~g} / \mathrm{L}$.

\section{Statistical analysis}

Normally distributed variables were expressed as mean and standard deviation (SD), while variables with nonGaussian distribution were expressed as median, range and 25 to 75 percentiles. The statistical software package SPSS, version 11.0, was used for statistical testing of the data.

\section{Results}

The clinical and biochemical data of the participants are shown in Table 1 . There was no significant age difference between males and females: mean age 30.0 (SD 8.5) years versus 31.0 (SD 7.2) years respectively. A substantial percentage of male and female participants (90\% and 93\% respectively) reported a sufficient regular intake of dairy products to satisfy their daily need for calcium. The percentage of females and males reporting regular exposure to sunlight were $68 \%$ and $65 \%$ respectively.

The serum creatinine level of males was significantly higher than in females, which is expected due to the higher body mass index of males. However, this elevated level of serum creatinine [85.6 (SD 12.5) $\mu \mathrm{mol} / \mathrm{L}$ ] was still within the laboratory reference ranges for males in this age group $(71-115 \mu \mathrm{mol} / \mathrm{L})$. There was no significant difference between males and females regarding fasting serum glucose, serum uric acid, total protein, albumin, phosphorous, calcium or alkaline phosphate levels. However, the mean values of serum calcium in both groups were towards the lower level of normal $(<2.2 \mathrm{mmol} / \mathrm{L})$. ALT was significantly higher in males than females, which may be due to a mild degree of fatty liver disease in some overweight males in the sample.

\begin{tabular}{|c|c|c|c|c|}
\hline \multicolumn{5}{|c|}{$\begin{array}{l}\text { Table } 1 \text { Clinical and biochemical characteristics of the study groups of male and } \\
\text { female Saudi Arabians }\end{array}$} \\
\hline \multirow{2}{*}{$\begin{array}{l}\text { Parameter } \\
\text { Mean (SD) age (years) }\end{array}$} & \multicolumn{2}{|c|}{ Males $(n=87)$} & \multicolumn{2}{|c|}{ Females $(n=52)$} \\
\hline & 30.0 & $(8.5)$ & 31.0 & $(7.2)$ \\
\hline Mean (SD) BMI (kg/m²) & 27.2 & (2.3) & 26.2 & $(2.4)$ \\
\hline Mean (SD) blood pressure $(\mathrm{mmHg})$ & 77.5 & (5.9) & 72.0 & (8.3) \\
\hline$\%$ with regular sun exposure & \multicolumn{2}{|c|}{65} & \multicolumn{2}{|c|}{68} \\
\hline$\%$ with regular intake of dairy products & \multicolumn{2}{|c|}{90} & \multicolumn{2}{|c|}{93} \\
\hline \multicolumn{5}{|l|}{ Laboratory parameters [mean (SD) values] } \\
\hline Haemoglobin $(\mathrm{g} / \mathrm{dL})$ & 16.1 & (1.5) & 14.8 & $(0.9)$ \\
\hline Random glucose (mmol/L) & 5.8 & $(0.5)$ & 5.5 & $(0.6)$ \\
\hline Urea $(\mathrm{mmol} / \mathrm{L})$ & 4.2 & $(2.7)$ & 5.1 & $(1.5)$ \\
\hline Creatinine (mmol/L) & 85.6 & $(12.5)^{*}$ & 56.6 & $(14.8)$ \\
\hline Uric acid $(\mu \mathrm{mol} / \mathrm{L})$ & 200.3 & $(64.8)$ & 191.4 & $(46.3)$ \\
\hline Calcium (mmol/L) & 2.12 & $(0.08)$ & 2.14 & $(0.07)$ \\
\hline Phosphorous (mmol/L) & 1.10 & $(0.15)$ & 1.01 & $(0.20)$ \\
\hline Alkaline phosphatase (U/L) & 93.1 & (29.6) & 74.4 & $(19.2)$ \\
\hline $\operatorname{ALT}(\mathrm{U} / \mathrm{L})$ & 46.1 & $(10.6)^{*}$ & 28.1 & $(7.0)$ \\
\hline Total protein $(\mathrm{g} / \mathrm{L})$ & 74.6 & $(4.4)$ & 68.8 & (4.9) \\
\hline Albumin (g/L) & 42.7 & $(2.4)$ & 39.3 & (3.3) \\
\hline PTH $(p g / m L)$ & 67.0 & $(35.3)^{*}$ & 47.5 & (19.6) \\
\hline $25(\mathrm{OH}) \mathrm{D}(\mathrm{ng} / \mathrm{mL})$ & 10.1 & $(4.6)$ & 9.9 & $(4.5)$ \\
\hline
\end{tabular}

${ }^{*} P<0.05$.

PTH conversion factor: $\mathrm{pg} / \mathrm{mL} \times 0.1053=\mathrm{pmol} / \mathrm{L} ; 25(\mathrm{OH}) \mathrm{D}$ conversion factor: $\mathrm{ng} / \mathrm{mL} \times 2.5=\mathrm{nmol} / \mathrm{L}$. $S D=$ standard deviation; $B M I=$ body mass index; $A L T=$ alanine transaminase $P T H=$ parathyroid hormone; $25(\mathrm{OH}) D=25$-hydroxyvitamin $D$.

Serum PTH levels were significantly higher in males than females $(P<0.01)$ : 67.0 (SD 35.3) versus 47.5 (SD 19.6) $\mathrm{pg} / \mathrm{mL}$ respectively. For males the range for PTH was from $19.8-204 \mathrm{pg} / \mathrm{mL}$ and for females from $12.5-93.8 \mathrm{pg} / \mathrm{mL}$.

Serum 25(OH)D levels were low; mean levels in males and females were 10.1 (SD 4.6) $\mathrm{ng} / \mathrm{mL}$ and 9.9 (SD 4.5) $\mathrm{ng} / \mathrm{mL}$ respectively (Figure 1 ). These $25(\mathrm{OH}) 3$ levels did not differ significantly between males and females.

PTH levels did not correlate with serum 25(OH)D levels in either male or female groups $(r=0.35, P=0.75$ and $r=0.11, P=0.44$ respectively). However, the serum 25(OH)D levels correlated with the serum calcium levels in both groups $(r=0.34, P=0.040$ and $r=0.302$, $P=0.03$ respectively).

As elevated serum PTH level reflects a state of either clinical or subclinical vitamin D deficiency to maintain normal serum calcium, subjects with increased
PTH level above the upper part of the reference ranges for PTH assay (i.e. $>68.0 \mathrm{pg} / \mathrm{mL}$ ) were excluded (30 males and 10 females) and the $25(\mathrm{OH})$ $\mathrm{D}$ data were reanalysed. The adjusted figures showed a serum $25(\mathrm{OH}) \mathrm{D}$ level of 10.1 (SD 4.5) ng/mL in males and $10.2(\mathrm{SD} 4.8) \mathrm{ng} / \mathrm{mL}$ in females, which was still within the deficiency range for serum 25(OH)D (Figure 2). There were no significant differences between males and females in these adjusted serum 25 $(\mathrm{OH})$ D levels $(P>0.05)$.

Serum alkaline phosphatase levels were not increased in either males or females participating in the study despite the low serum $25(\mathrm{OH}) \mathrm{D}$ level reported.

\section{Discussion}

The current study evaluated serum $25(\mathrm{OH}) \mathrm{D}$ and its relationship to PTH 

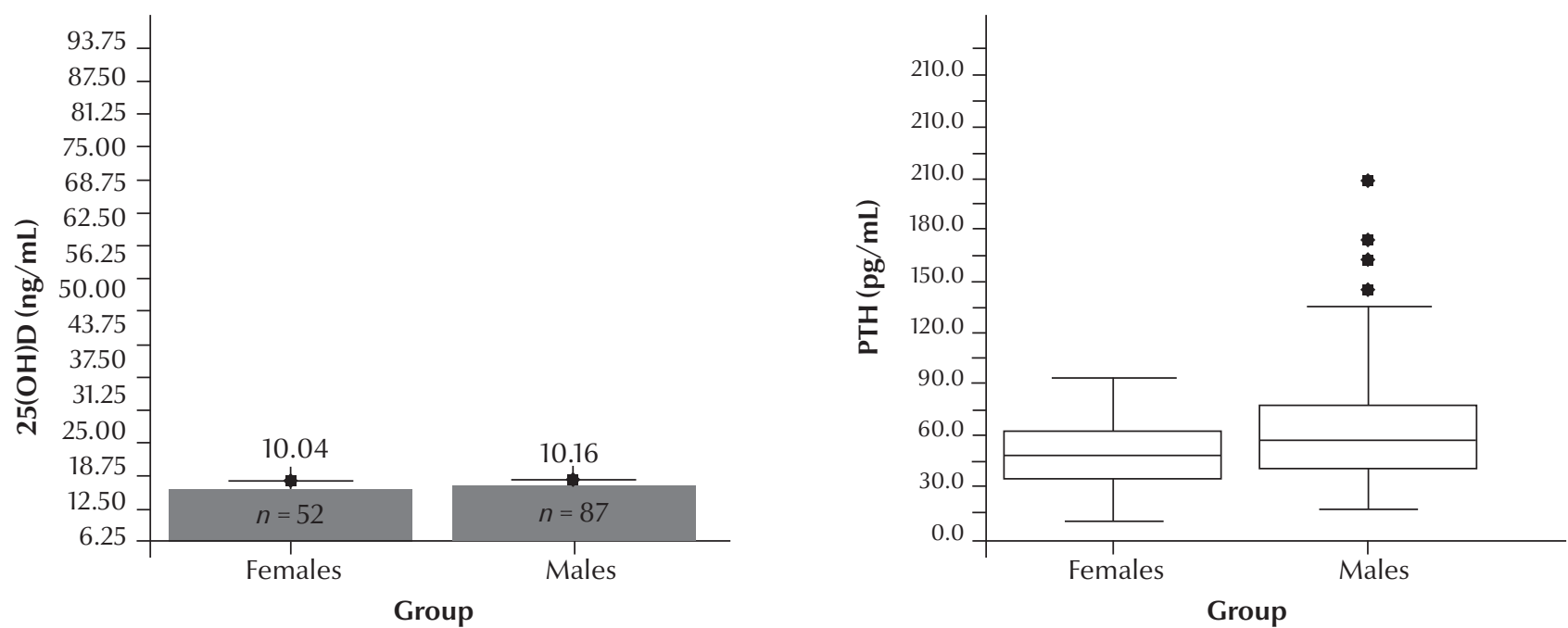

Figure 1 Serum levels of 25-hydroxyvitamin $\mathrm{D}[25(\mathrm{OH}) \mathrm{D}]$ and parathyroid hormone (PTH) in the study groups of male and female Saudi Arabians. Boxplots show median values with 25 th to 75 th percentiles and minimum and maximum values [O $=$ outliers (values larger than the upper quartile plus 1.5 times the interquartile range); ${ }^{*}=$ extremes (values larger than the upper quartile plus 3 times the interquartile range)]

in a cohort of healthy Saudi subjects. Vitamin D plays a critical role in bone metabolism and many cellular and immunological processes [12]. Low levels of vitamin $\mathrm{D}$ have been associated with various chronic diseases, especially osteoporosis [13,14]. Vitamin D is synthesized in the skin through exposure to UVB radiation, and solar radiation is the primary source of vitamin $\mathrm{D}$ for most people [15]. Vitamin D is also acquired from the diet from sources where it occurs naturally (such as fatty fish, fish oil and eggs), from fortified products (such as milk and orange juice) and from supplements [16]. In areas far from the equator the amount of UVB available from sunlight during the winter months is inadequate to allow cutaneous vitamin D synthesis. However, in Saudi Arabia there should be sufficient sunlight to allow for vitamin D synthesis [17]. Different factors can affect serum vitamin D level, including skin pigmentation (synthesis decreases in dark skin), ageing (vitamin D synthetic capacity decreases with ageing), the use of sun blocking agents, chronic renal, liver and gastrointestinal tract diseases and the use of certain medications (e.g. anticonvulsants) [18]. Low levels of serum vitamin $\mathrm{D}$ and calcium exert a positive feedback on serum PTH to increase serum calcium level that stimulates the conversion of $25(\mathrm{OH}) \mathrm{D}$ to vitamin $\mathrm{D}$ and to increase the absorption of vitamin $\mathrm{D}$ from the gut. Different
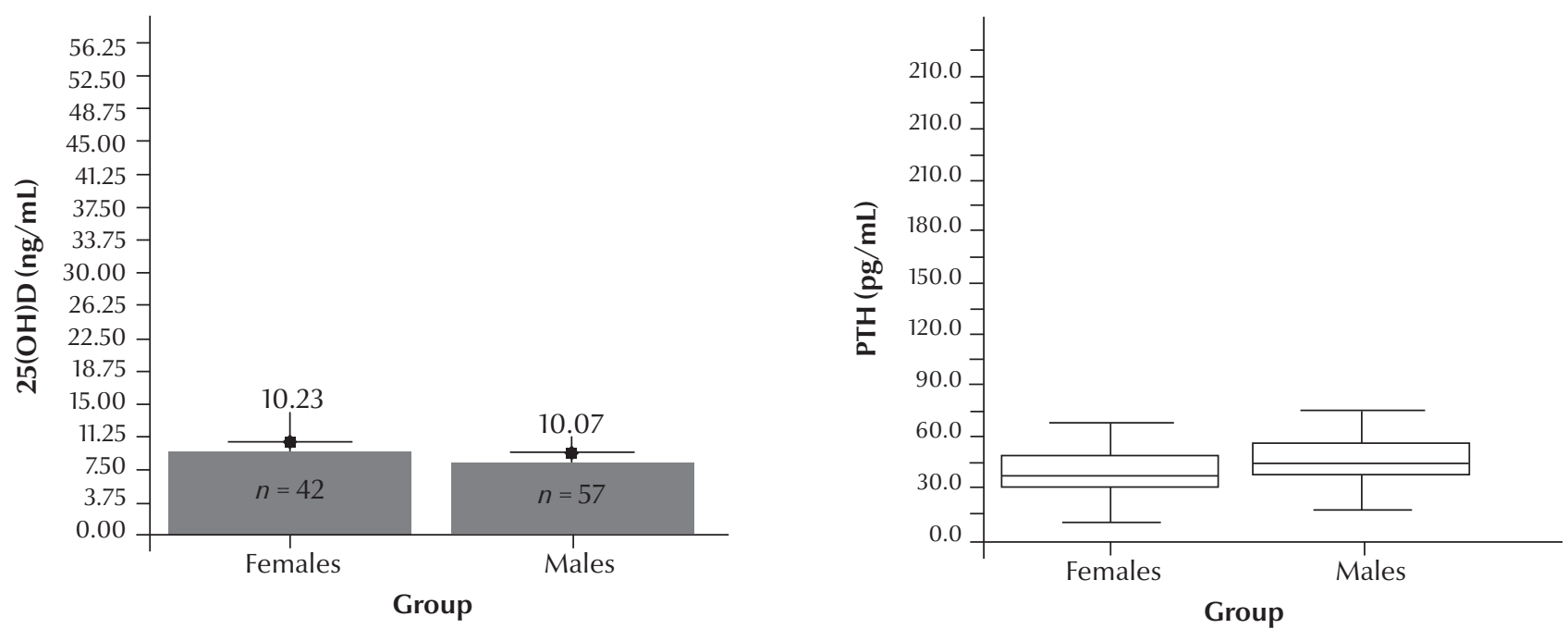

Figure 2 Serum levels of serum 25-hydroxyvitamin $\mathrm{D}[25(\mathrm{OH}) \mathrm{D}]$ and parathyroid hormone $(\mathrm{PTH})$ in the study groups of male and female Saudi Arabians after exclusion of subjects with elevated PTH level ( $>68 \mathrm{pg} / \mathrm{mL}$ ). Boxplots show median values with 25 th to 75 th percentiles and minimum and maximum values 
studies that have evaluated the status of vitamin $D$ in different ethnic populations suggest concentrations $<10-11 \mathrm{ng} / \mathrm{mL}$ as deficiency $[19,20]$. Lower levels are expected to be associated with calcium malabsorption and hypocalcaemia, severe hyperparathyroidism and vitamin D rickets or osteomalacia [21].

The current study found a marked deficiency in the serum 25(OH)D level in both male and female blood donors. Importantly, serum 25(OH)D did not correlate with PTH level. The low level of $25(\mathrm{OH}) \mathrm{D}$ found in the current study could not be explained by low intake or poor sun exposure, as a substantial proportion of the participants in this study ( $90 \%$ of males and $93 \%$ of females) reported a sufficient nutritional intake of vitamin D and nearly $67 \%$ of them had regular exposure to UV sunlight. A possible explanation of this markedly low 25(OH)D level in both males and females is a racial difference in vitamin D concentration or a genetic predisposition to vitamin D deficiency among Saudi Arabians. Pal et al. reported an extremely high prevalence of $25(\mathrm{OH}) \mathrm{D}$ deficiency in Asian populations living in the United Kingdom and hypothesized that there is a genetic predisposition to 25(OH)D deficiency among Asians [22]. Similarly Maeda et al. and Peters et al. have reported deficient levels of vitamin $D$ in healthy adults and adolescents in Brazil $[23,24]$. They attributed these low levels to poor intake of vitamin $\mathrm{D}$ as there is abundant exposure to sunlight in Brazil. Vieth et al. studied a cohort of young healthy Canadian women (aged 18-35 years) in Toronto and found similarly low levels of vitamin D $(<40$ $\mathrm{nmol} / \mathrm{L}, 16 \mathrm{ng} / \mathrm{mL}$ ) in a substantial proportion of participants during the winter months [25]. Rucker et al. reported similar results in Canadians of European ancestry [26].

Another possible explanation of these low 25(OH)D levels in our cohort of patients is that women in Saudi Arabia wear the traditional Islamic veil, which prevents the penetration of the UVB light needed for the synthesis of vitamin D. Certainly Hobbs et al. reported severe vitamin $\mathrm{D}$ deficiency in Arab-American women who wear the veil [27]. However, this does not explain why Saudi Arabian men had similarly low levels of vitamin D. Even if we hypothesize that Saudi Arabians have a mildly dark skin which could limit the penetration of UVB light, over $90 \%$ of participants reported an adequate intake of calcium and vitamin $\mathrm{D}$ rich food products which should compensate for a lack of cutaneous synthesis of vitamin D. This suggests that there are racial differences in the absorption of calcium and vitamin $D$ from the gut.

An important finding is that we could not find a correlation between serum 25(OH)D and PTH levels, and the mean serum $25(\mathrm{OH}) \mathrm{D}$ level was still in the lower end of the reference range even after exclusion of patients with high PTH levels. In other words, although vitamin D levels were markedly reduced, the PTH level was not increased in the majority of participants. This finding agrees with Haarburger et al., who found that the subnormal $25(\mathrm{OH}) \mathrm{D}$ level in their South African cohort was also not related to hypocalcaemia or a significant rise in PTH. They suggested that $25(\mathrm{OH})$ $\mathrm{D}$ measurements should be requested when vitamin $\mathrm{D}$ deficiency is clinically suspected, irrespective of calcium and PTH biochemical results [28].

This study has presented a preliminary evaluation of vitamin $\mathrm{D}$ status in young, apparently healthy Saudi Arabians. Our data showed that the prevalence of 25(OH)D deficiency was high among Saudi Arabians and suggest the need to increase the fortification of food products with vitamin $\mathrm{D}$ and screening for vitamin $\mathrm{D}$ deficiency among not only the elderly but also young Saudi adults to prevent future morbidity. Future studies should include evaluation of bone mineral density and comparison with the reference range for adults of similar age and sex. Another important point is to stratify the reference ranges according to factors such as season and ethnic background. Other studies are needed to measure the degree of skin pigmentation quantitatively and its correlation to vitamin D level and to monitor biochemical parameters after vitamin $\mathrm{D}$ supplementation. These may help to establish if there are racial differences in vitamin $\mathrm{D}$ handling.

\section{References}

1. Food and Nutrition Board, Institute of Medicine. Dietary reference intakes for calcium, magnesium, phosphorus, vitamin $D$, and fluoride. Washington DC, National Academy Press, 1997.

2. Trivedi DP, Doll R, Khaw KT. Effect of four monthly oral vitamin D3 (cholecalciferol) supplementation on fractures and mortality in men and women living in the community: randomised double blind controlled trial. BMJ (Clinical Research Ed.), 2003, 326:469-474.

3. Eastell R et al. Relationship of early changes in bone resorption to the reduction in fracture risk with risedronate. Journal of Bone and Mineral Research, 2003, 18:1051-1056.
4. Chan J, Jaceldo-Siegl K, Fraser GE. Serum 25-hydroxyvitamin D status of vegetarians, partial vegetarians, and nonvegetarians: the Adventist Health Study-2. American Journal of Clinical Nutrition, 2009, 89:1686S-1692S.

5. Aloia JF et al. Vitamin D intake to attain a desired serum 25hydroxyvitamin D concentration. American Journal of Clinical Nutrition, 2008, 87:1952-1958.

6. Heaney RP. Functional indices of vitamin D status and ramifications of vitamin D deficiency. American Journal of Clinical Nutrition, 2004, 80(Suppl.):1706S-1709S.

7. Vieth R. Vitamin D supplementation, 25-hydroxyvitamin D concentrations, and safety. American Journal of Clinical Nutrition, 1999, 69:842-856. 
8. Lips P et al. A global study of vitamin D status and parathyroid function in postmenopausal women with osteoporosis: baseline data from the multiple outcomes of raloxifene evaluation clinical trial. Journal of Clinical Endocrinology and Metabolism, 2001, 86:1212-1221.

9. Lips P et al. A global study of vitamin D status and parathyroid function in postmenopausal women with osteoporosis: baseline data from the multiple outcomes of raloxifene evaluation clinical trial. Journal of Clinical Endocrinology and Metabolism, 2001, 86:1212-1221.

10. Sahota $\mathrm{O}$ et al. The relationship between vitamin $\mathrm{D}$ and parathyroid hormone: calcium homeostasis, bone turnover, and bone mineral density in postmenopausal women with established osteoporosis. Bone, 2004, 35:312-319.

11. Nakamura $\mathrm{K}$ et al. Vitamin D status, bone mass, and bone metabolism in home-dwelling postmenopausal Japanese women: Yokogoshi study. Bone, 2008, 42:271-277.

12. MacDonald PN. Molecular biology of the vitamin D receptor. In: Holick MF, ed. Vitamin D: molecular biology, physiology, and clinical applications. Totowa, new Jersey, Humana Press; 1999:109-128.

13. Holick MF. Vitamin D: important for prevention of osteoporosis, cardiovascular heart disease, type 1 diabetes, autoimmune diseases, and some cancers. Southern Medical Journal, 2005, 98:1024-1027.

14. Holick MF. The vitamin D epidemic and its health consequences. Journal of Nutrition, 2005, 135:2739S-2748S.

15. Grant WB, Holick MF. Benefits and requirements of vitamin D for optimal health: a review. Alternative Medicine Review, 2005, 10:94-111.

16. Holick MF. Vitamin D deficiency. New England Journal ofMedicine, 2007, 357:266-281.

17. Webb AR, Kline L, Holick MF. Influence of season and latitude on the cutaneous synthesis of vitamin D3: exposure to winter sunlight in Boston and Edmonton will not promote vitamin D3 synthesis in human skin. Journal of Clinical Endocrinology and Metabolism, 1988, 67:373-378.
18. MacLaughlin J, Holick MF. Aging decreases the capacity of human skin to produce vitamin D3. Journal of Clinical Investigation, 1985, 76:1536-1538.

19. Vieth $\mathrm{R}$ et al. Wintertime vitamin $\mathrm{D}$ insufficiency is common in young Canadian women, and their vitamin D intake does not prevent it. European Journal of Clinical Nutrition, 2001, 55:1091-1097.

20. Standing Committee on the Scientific Evaluation of Dietary Reference Intakes. Dietary reference intakes for calcium, phosphorus, magnesium, vitamin d, and fluoride. Washington DC, National Academy Press; 1997.

21. Need AG et al. Vitamin D status: effects on parathyroid hormone and 1, 25-dihydroxyvitamin D in postmenopausal women. American Journal of Clinical Nutrition, 2000, 71:1577-1581.

22. Pal BR et al. Distribution analysis of vitamin D highlights differences in population subgroups: preliminary observations from a pilot study in UK adults. Journal of Endocrinology, 2003, 179:119-129.

23. Maeda SS et al. The effect of sun exposure on 25-hydroxyvitamin D concentrations in young healthy subjects living in the city of São Paulo, Brazil. Brazilian Journal ofMedical and Biological Research, 2007, 40:1653-1659.

24. Peters BS et al. Prevalence of vitamin D insufficiency in Brazilian adolescents. Annals of Nutrition and Metabolism, 2009, 54:15-21.

25. Gozdzik A et al. Low wintertime vitamin D levels in a sample of healthy young adults of diverse ancestry living in the Toronto area: associations with vitamin D intake and skin pigmentation. BMC Public Health, 2008, 8:336.

26. Rucker D et al. Vitamin D insufficiency in a population of healthy western Canadians. Canadian Medical Association Journal, 2002, 166:1517-1524.

27. 27. Hobbs RD et al. Severe vitamin D deficiency in Arab-American women living in Dearborn, Michigan. Endocrine Practice, 2009, 15:35-40.

28. Haarburger D et al. Relationship between vitamin D, calcium and parathyroid hormone in Cape Town. Journal of Clinical Pathology, 2009, 62:567-569. 